\title{
Pathogen-Induced Production of the Antifungal AFP Protein from Aspergillus giganteus Confers Resistance to the Blast Fungus Magnaporthe grisea in Transgenic Rice
}

\author{
Ana Beatriz Moreno, ${ }^{1}$ Gisela Peñas, ${ }^{2}$ Mar Rufat, ${ }^{1}$ Juan Manuel Bravo, ${ }^{1}$ Montserrat Estopà, ${ }^{2}$ \\ Joaquima Messeguer, ${ }^{2}$ and Blanca San Segundo' \\ Consorcio Laboratorio CSIC-IRTA de Genética Molecular Vegetal: ${ }^{1}$ Departamento de Genética Molecular, Instituto de \\ Biología Molecular de Barcelona, CSIC. Jordi Girona 18, 08034 Barcelona, Spain; ${ }^{2}$ Departamento de Genética Vegetal, \\ IRTA Centro de Cabrils. Carretera de Cabrils s/n, Cabrils 08348, Barcelona, Spain
}

Submitted 23 February 2005. Accepted 24 April 2005.

Rice blast, caused by Magnaporthe grisea, is the most important fungal disease of cultivated rice worldwide. We have developed a strategy for creating disease resistance to M. grisea whereby pathogen-induced expression of the afp (antifungal protein) gene from Aspergillus giganteus occurs in transgenic rice plants. Here, we evaluated the activity of the promoters from three maize pathogenesis-related $(P R)$ genes, $Z m P R 4, m p i$, and $P R m s$, in transgenic rice. Chimeric gene fusions were prepared between the maize promoters and the $\beta$-glucuronidase reporter gene (gus $A$ ). Histochemical assays of GUS activity in transgenic rice revealed that the $\mathrm{ZmPR} 4$ promoter is strongly induced in response to fungal infection, treatment with fungal elicitors, and mechanical wounding. The $Z m P R 4$ promoter is not active in the seed endosperm. The mpi promoter also proved responsiveness to fungal infection and wounding but not to treatment with elicitors. In contrast, no activity of the PRms promoter in leaves of transgenic rice was observed. Transgenic plants expressing the afp gene under the control of the ZmPR4 promoter were generated. Transformants showed resistance to $M$. grisea at various levels. Our results suggest that pathogen-inducible expression of the afp gene in rice plants may be a practical way for protection against the blast fungus.

Additional keywords: Oryza sativa, Zea mays.

Most agricultural crop species suffer from a vast array of fungal diseases that cause severe yield losses all over the world. Rice blast, caused by the fungus Magnaporthe grisea (Herbert) Barr (anamorph Pyricularia grisea), is the most devastating disease of cultivated rice (Oryza sativa L.), due to its

Corresponding author: B. San Segundo; E-mail: bssgmb@cid.csic.es; Fax: 34932045904.

The nucleotide sequence data is available from the EMBL nucleotide sequence database under the accession number AJ969166 Zea mays PR4 gene promoter.

* The $\boldsymbol{e}$-Xtra logo stands for "electronic extra" and indicates that Figures $3,4,6$, and 7 appear in color on-line. widespread distribution and destructiveness (Ou 1985). Breeding of durable resistance to this fungus is a difficult problem not only because of the high degree of pathogenic variability of $M$. grisea but also because of the large number of fungal races encountered in the field population. Conventional control of rice blast depends on the use of chemically synthesized fungicides. However, the repeated use of such chemicals has several drawbacks, such as their lack of specificity, increased incidence of development of resistance upon prolonged application, and the adverse impact on human health and environment.

Genetic engineering of plants by transferring a gene of interest has now been accepted as a method of choice for directional improvement and development of disease-resistant plants. The simplest means for genetic engineering of resistance to fungal diseases entails the constitutive expression of antifungal genes in transgenic plants. Thus, constitutive promoters, such as the CaMV35S (Cauliflower mosaic virus) or the ubiquitin promoter, have been successfully used to drive expression of a spectrum of antifungal genes of both plant and nonplant origin in transgenic plants (Coca et al. 2004; Epple et al. 1997; Datta et al. 1999; Gao et al. 2000; Kanzaki et al. 2002; Lorito et al. 1998). These promoters may, however, be suitable for proofof-concept experiments to assess the effectiveness of transgene expression but present a number of potential drawbacks for actual use in genetically improved crops. Instead, the selective induction of the transgene at the site where the transgene product is needed and only when needed represents a more desirable strategy for protection of crop species against pathogens. However, the success of strategies for regulated transgene expression based on the introduction of an antifungal gene into the plant genome under the control of a pathogen-inducible promoter requires that the pathogen-controlled production of the antifungal compound occurs rapidly and locally at the infection site. Another undesirable side effect led by the use of constitutive promoters comes from the accumulation of the transgene product in plant organs used for human or animal consumption. Thus, in addition to pathogen-inducibility, the promoter used to direct transgene expression must not be active in eatable organs.

Plants are known to produce numerous antimicrobial proteins to defend themselves from pathogens, the induction of the expression of pathogenesis-related $(P R)$ genes being an 
ubiquitous defense response of plants to pathogen attack (Dangl and Jones 2001; Nimchuk et al. 2003; Somssich and Hahlbrock 1998; van Loon 1985; van Loon and van Strien 1999). There are a large number of pathogen-inducible $P R$ genes, and their promoters are known to contain multiple cisacting elements involved in the pathogen-inducibility of the expression of these genes. Two groups of pathogen-inducible cis-acting elements, the GCC box (AGCCGCC) and the W box ([T]TGAC $[\mathrm{C} / \mathrm{T}]$ ), are well studied (Eulgem et al. 2000; Lebel et al. 1998; Rushton and Sommssich 1998; Rushton et al. 2002). Considering the pathogen-inducibility of $P R$ genes, their promoters are of special interest for designing protective strategies involving inducible expression of antimicrobial genes in crop species. Most studies on pathogen-inducible genes have concerned dicotyledonous plants. However, promoters from pathogen-inducible genes from dicotyledonous species, usually are not useful when approaching transgene expression in monocotyledonous plants. In maize, the induction of the expression of certain $P R$ genes in response to fungal infection has been described by our group (Bravo et al. 2003; Campo et al. 2004; Casacuberta et al. 1991; Cordero et al. 1994a). More particularly, the fungal-inducible expression of the ZmPR4 gene encoding a class II chitinase of the PR-4 family of PR proteins, the mpi gene encoding a proteinase inhibitor (PR-6 family of PR-proteins), and the PRms gene encoding a member of the PR-1 family of PR proteins has been reported.

On the other hand, the production of antimicrobial proteins is not restricted to plant species but seems to be ubiquitous in nature (Zasloff 2002). In particular, the soil fungus Aspergillus giganteus has been reported to produce a basic, low-molecular-weight protein (51 amino acids), the AFP protein, showing antifungal properties against plant pathogens (Lacadena et al. 1995; Moreno et al. 2003; Vila et al. 2001). In a recent study, we have shown that rice plants can be engineered for resistance against the blast fungus by expression of the A. giganteus afp gene under the control of the constitutive maize ubiquitin promoter (Coca et al. 2004).

This study focused on two objectives. First, to determine the functionality and fungal inducibility of promoters from maize genes in stable transformed rice plants, and second, to determine whether a fungal-inducible promoter directs sufficient levels of expression of an antifungal gene, namely the afp gene, to protect transgenic rice from the blast fungus $M$. grisea. The promoters from the ZmPR4, mpi, and PRms genes from maize (Casacuberta et al. 1991; Cordero et al. 1994a and b; Raventós et al. 1995) were selected for this study. The expression pattern of the three maize promoters in transgenic rice was evaluated using the gusA reporter gene. Moreover, transgenic rice plants expressing the afp gene from A. giganteus under the control of the $Z m P R 4$ promoter were produced. The transgenic plants obtained displayed enhanced resistance to the blast fungus $M$. grisea.

\section{RESULTS}

\section{Isolation and characterization of the $\mathrm{ZmPR4}$ gene.}

A genomic clone containing the $Z m P R 4$ gene sequence was isolated from a lambda EMBL3 library of Zea mays, using the ZmPR4 cDNA fragment described by Bravo and associates (2003) as probe. The ZmPR4 gene encodes a class II chitinase protein from maize, a member of the PR4 family of PR proteins. Nucleotide sequence analysis of the genomic clone revealed that it contained the entire coding as well as 5'and $3^{\prime}$ flanking regions of the $Z m P R 4$ gene. In comparing the genomic and the cDNA sequences, an intron of $95 \mathrm{nt}$ in length is found within the coding sequence of the ZmPR4 gene (Fig.
1A). Members of the PR4 family of PR proteins, the class I and II PR4 chitinases, all have an intron at this position. The assignment of the transcription start site, which locates $81 \mathrm{nt}$ upstream of the translation start site, was made by taking into account the longest $Z m P R 4$ cDNA sequence previously reported (Bravo et al. 2003) and also by homology with the consensus sequences for the transcription initiation sites described for plant genes (Joshi 1987).

Sequence analysis of the $\mathrm{ZmPR}$, mpi, and PRms promoters.

Close inspection of the 5'-flanking nucleotide sequence of the $Z m P R 4$ gene revealed the presence of sequences identical to previously identified cis elements, which are known to be involved in stress-induced expression of plant defense genes. Location of these elements is shown in Figure 1A. In the ZmPR4 promoter, a W-box element, TTTGACT, in reverse orientation was found at position -864 to $-858 \mathrm{bp}$ upstream of the putative transcription start site. Of interest, an elicitorresponsive element (ERE) ATTGACC was located in reverse orientation at position -285 to -279 of the ZmPR4 promoter sequence. This ERE is also found at position -246 in the PRms promoter (Raventós et al. 1995). In addition, multiple W box TGAC core sequences, either in direct or reverse orientation, are present in the ZmPR4 promoter (TGAC/GTCA). W-box elements have been shown to be important cis-acting elements in many pathogen-activated genes. Finally, several regulatory sequence motifs that are known to mediate the transcriptional activation of wound- and methyl jasmonate (MeJA)-inducible genes were identified in the ZmPR4 promoter (GAGTA, TGACG, and CGTCA).

Concerning the mpi promoter, a genomic clone containing the mpi gene from maize had been previously identified by our group (Cordero et al. 1994b). Moreover, the -689 to +197 promoter fragment of the mpi gene, named the $C 1$ mpi promoter, has been shown to confer wound-inducible expression to the gus reporter gene in transgenic rice (Breitler et al. 2001). To identify motifs potentially involved in fungal-responsive expression of $m p i$, the nucleotide sequence of the mpi promoter region extending to nucleotide $-1,872$ upstream of the translation start site was obtained. Interestingly, two W-boxes (CTTGACT) were identified at positions $-1,471$ and -786 of the mpi promoter (Fig. 1A). Multiple copies of either MeJA, wound-responsive elements, or both in either direct or reverse orientation (GAGTA and TACTC) were found in the $-1,872$ to +197 mpi promoter fragment (Fig. 1A).

Finally, the -736 to +53 fragment of the PRms promoter was also used in this study. This $P R m s$ promoter region is known to contain the ATTGACC element (ERE) located at position -246 (Fig. 1A). This cis-acting element was found to be necessary and sufficient to mediate elicitor responsiveness to the maize PRms gene in barley aleurone protoplasts (Raventós et al. 1995). An additional regulatory sequence motif, a W-box (TTTGACT) is present at position -286 of the PRms promoter.

\section{Production of transgenic rice containing the promoter-gus gene fusions.}

For functional characterization of the three maize promoters in transgenic rice, transcriptional fusions between each maize promoter and the $\beta$-glucuronidase reporter gene ( $g u s A$ ) were prepared. A schematic representation of the plant expression vectors used for production of promoter-gusA lines is presented in Figure 1B. Rice plants were transformed either by Agrobacterium-mediated transformation (ZmPR4-gus gene fusion) or by particle bombardment (mpi:gus and PRms:gus gene fusions).

For production of transgenic rice containing the ZmPR4:gus gene fusion, 300 calli from cv. Senia were cocultured with the EAH105 Agrobacterium strain bearing the $p C Z m P R 4:: g u s:: n o s$ 
A
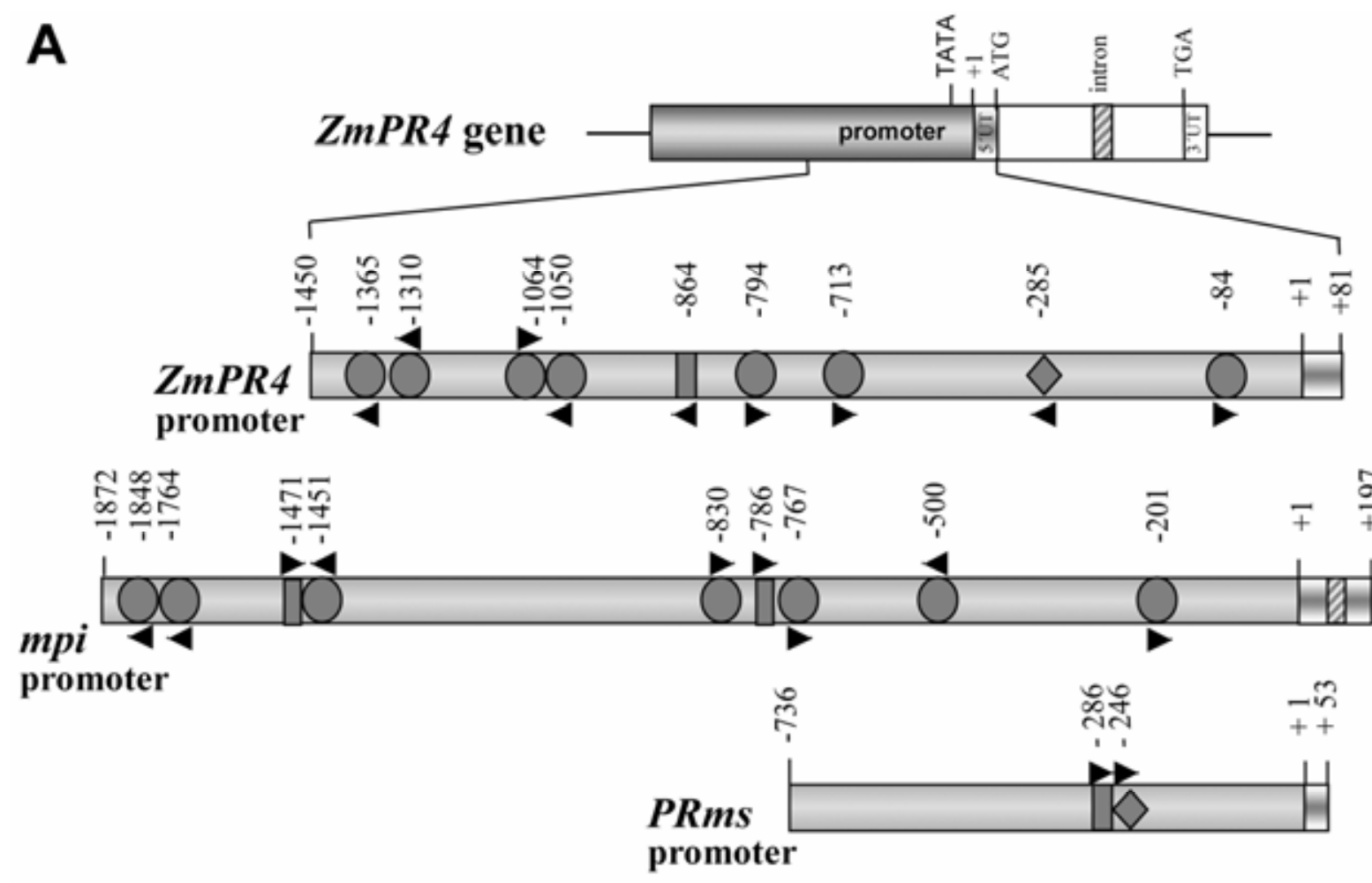

B

\section{pCZmPR4::gus::nos}
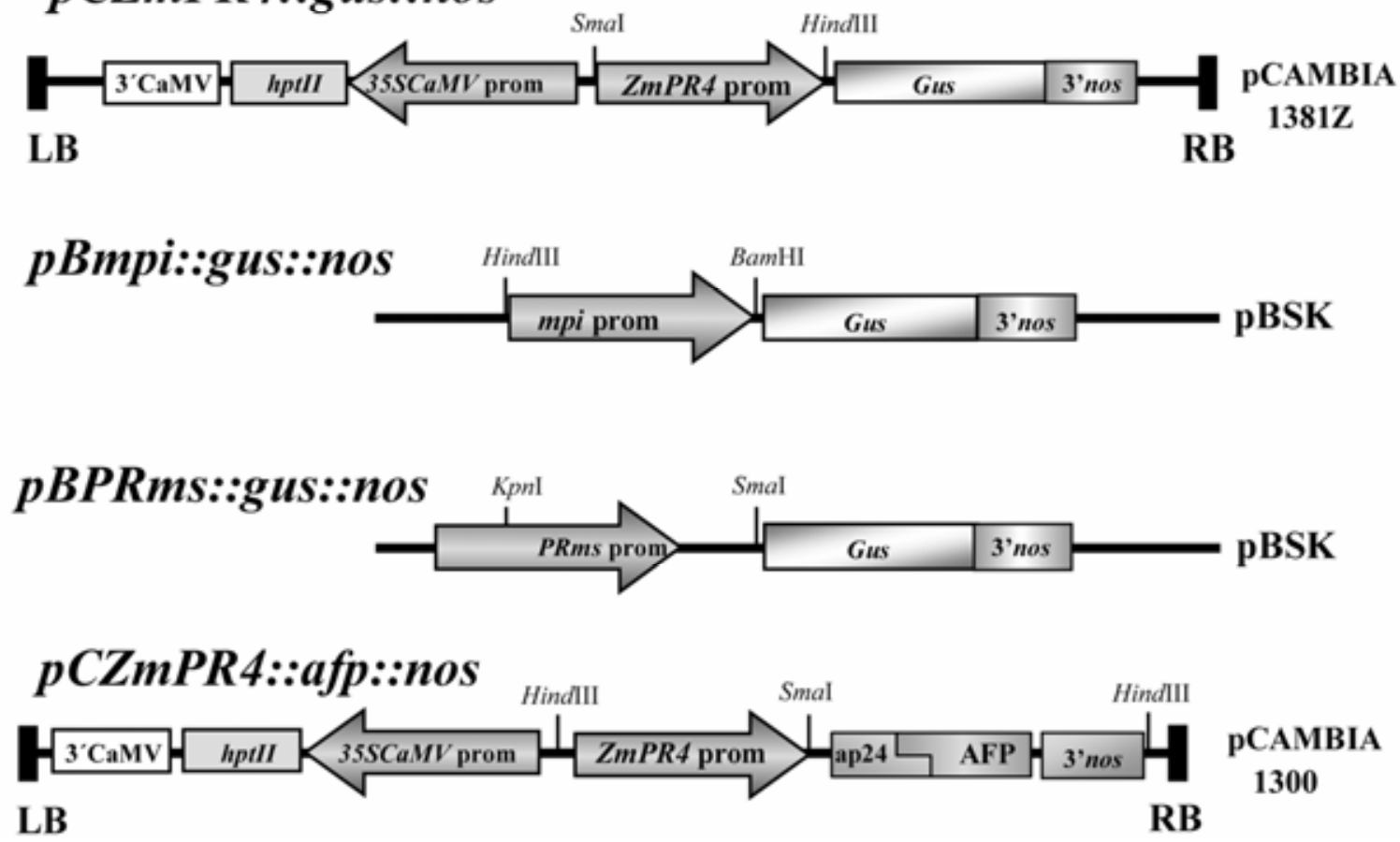

Fig. 1. Structural features of the promoters from the maize ZmPR4, mpi, and PRms genes and constructs used for rice transformation. A, Diagrammatic representation of the ZmPR4, mpi, and PRms maize promoters. Striped and open boxes in the ZmPR4 gene denote the intron and coding regions, respectively. The shaded areas represent the promoter sequence. Location of the putative pathogen- and wound-inducible cis-acting elements identified in the $Z m P R 4, m p i$, and PRms promoters are indicated as follows: the rectangular dark gray boxes indicate the W box (C/TTTGACT/C), the dark gray diamonds indicate ERE (ATT GACC), and the dark gray ovals indicate the methyl jasmonate- and wound-responsive elements (GAGTA; TGACG; CGTCA). Arrows at the bottom indicate the orientation, direct or reverse, of the cis-element. B, Components of the various constructs used for functional analysis of maize promoters, the ZmPR4:gus, mpi:gus, and PRms:gus gene fusions. The construct used for fungal-inducible expression of the afp gene in transgenic rice, $p C Z m P R 4:: a f p:: n o s$, is shown at the botton. $h p t I I=$ hygromycin phosphotransferase; $\mathrm{RB}=$ right border; $\mathrm{LB}=$ left border; $35 \mathrm{SCaMV}$ prom $=35 \mathrm{~S}$ cauliflower mosaic virus promoter; 3 CaMV $=$ cauliflower mosaic virus terminator; 3'nos = nopaline synthase terminator. 
construct. The hptII gene encoding resistance to hygromycin that is present in the parent pCAMBIA $1381 \mathrm{Z}$ vector served as the selectable marker in rice transformation. A total of 86 ZmPR4:gus plants were regenerated from hygromycin-resistant cell lines.

For production of transgenic rice harboring the mpi:gus gene fusion, a total of 300 embryogenic calli were cobombarded with the pBmpi::gus::nos and pILTAB227 plasmids and 70 plants were regenerated from hygromycin-resistant cell lines. Finally, 200 embryogenic calli were cobombarded with the pBPRms:gus:nos and pILTAB plasmids and 23 transformants were regenerated for this construct.

All transgenic rice plants harboring promoter:gus fusions, the ZmPR4:gus, mpi:gus, and PRms:gus lines, exhibited wildtype morphology and growth when compared with nontransgenic plants.

Southern blot analyses were carried out to determine the copy number and integration patterns of the ZmPR4:gus, mpi:gus, and PRms:gus transgenes. Transgenic T0 ZmPR4:gus lines, which were generated by Agrobacterium-mediated transformation, had one or two copies of the transgene inserted into their genomes (results not shown; Southern blot analysis of T2 transgenic lines is shown in Figure 2). Those T0 lines showing one or two integration events were selected to obtain homozygous transgenic lines in the T2 generation. On the other hand, multiple copies of the transgene integrated in the genome of the mpi:gus and PRms:gus lines, as it is usually observed in transgenic plants produced by particle bombardment. Stability of integration and inheritance of the transgenes was monitored by Southern blot analysis of the progeny plants (up to the T2 generation). Figure 2 shows the results obtained on the Southern blot analysis of representative $\mathrm{T} 2$ homozygous $\mathrm{ZmPR} 4$ : gus (R32-17, R32-2, and R32-14) and mpi:gus (M17-8 and M164) lines.

\section{Histochemical analysis of GUS activity in tissues of transgenic rice.}

GUS histochemical assays were conducted on vegetative and reproductive organs of $\mathrm{T} 2$ homozygous transgenic rice plants harboring promoter-gus $A$ gene fusions. As shown in Figure $3 \mathrm{~A}$, the $\mathrm{ZmPR} 4$ promoter had no background expression in leaves, but GUS staining was observed at the cutting sites of the leaf blades. Equally, no GUS activity was detected in the stem of the ZmPR4:gus lines, except at the cutting sites (Fig. 3B). In the root system of ZmPR4:gus rice plants, GUS staining was observed at the locus of initiation of lateral roots (Fig. 3C).

A more detailed study on the wound-inducibility of the ZmPR4 promoter in tissues of transgenic rice plants was carried out. Towards this end, leaves of soil-grown ZmPR4:gus plants were wounded by making perpendicular cuts on the leaf blade and were subjected to GUS histochemical assays at different times after wounding. Representative results of GUS activity in wounded leaves of the ZmPR4:gus rice lines are shown in Figure 3D. At $10 \mathrm{~min}$ after wounding, intense staining at the cut edge of the wound (approximately $0.2 \mathrm{~mm}$ ) was observed, suggesting strong local wound-response of the $\mathrm{ZmPR} 4$ promoter in rice plants. Responsiveness to wounding was observed in both young and mature leaves of ZmPR4:gus rice lines. Roots, when cut longitudinally, also showed strong activity of this promoter (Fig. 3E). Most probably, the GUS activity that is observed in unwounded roots at the sites of lateral root emergence (Fig. 3C) is the consequence of the wound produced into the root tissue by the emerging lateral root. A similar pattern of wound-induced GUS activity was observed in three independent ZmPR4: gus lines.

Histochemical GUS analysis was also performed in mature seeds from ZmPR4:gus plants (Fig. 3F). No activity was detected in seeds that were manually dehulled and incubated in the staining solution, even after an overnight period of incubation in the X-gluc substrate (Fig. 3F, left panel). In seeds that were longitudinally cut before incubation in staining solution, a low level of GUS activity was detected at the epithelium of the embryo scutellum (Fig. 3F, middle panel). Finally, intact dehulled seeds that had been heavily damaged by brushing and by making small cuts before staining for GUS activity, stained faintly only in the seed tegument. Of interest, ZmPR4 promoter activity was not observed in the endosperm tissue of the mature rice seed from ZmPR4:gus lines under any of the wound regimes here assayed. For a comparison, seeds from transgenic plants harboring the 35SCaMV:gus construct were also longitudinally cut and stained for GUS activity. Endosperms of seeds from 35SCaMV:gus plants stained deeply in blue.
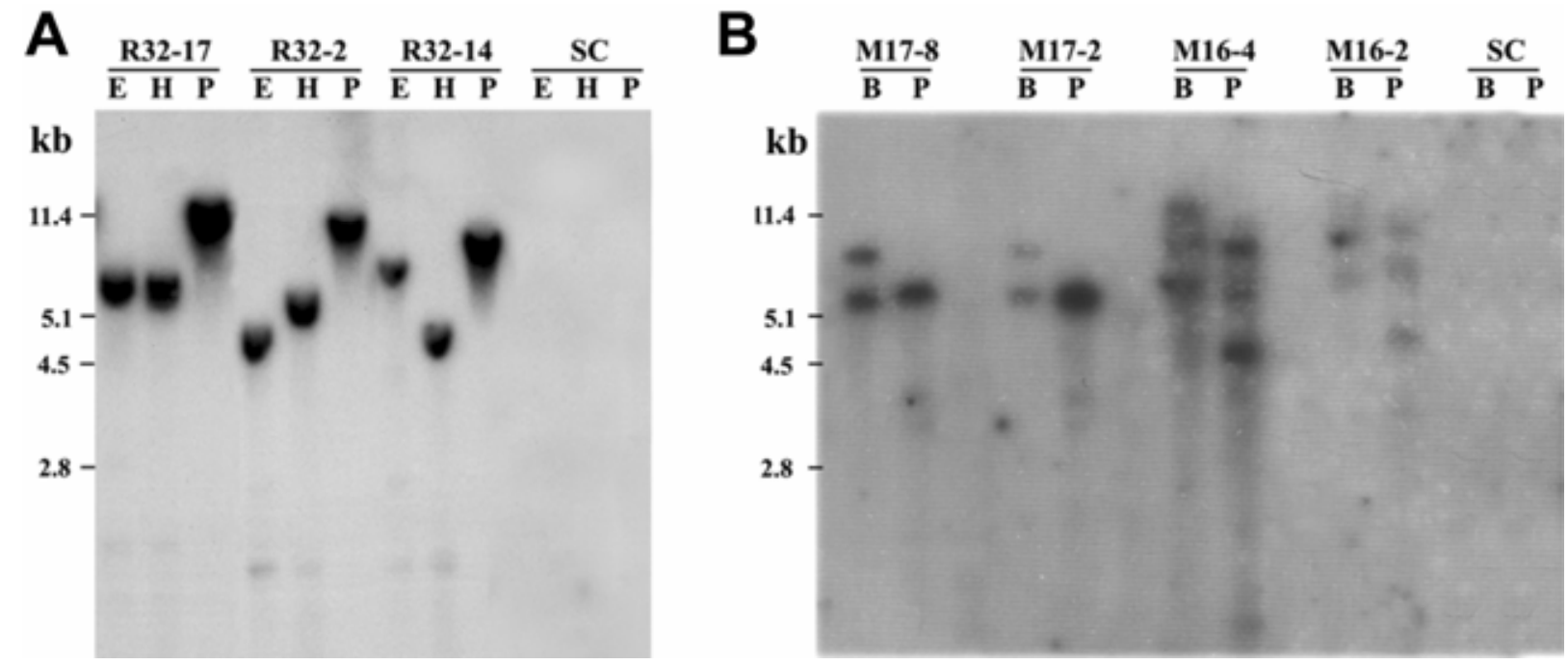

Fig. 2. Southern blot analysis of the ZmPR4:gus and mpi:gus rice plants. Genomic DNA (10 $\mu$ g) from T2 transgenic lines was digested with restriction enzymes and was subjected to electrophoresis through a $0.8 \% \mathrm{wt} / \mathrm{vol}$ agarose gel. DNA samples were transferred to nylon membrane and were hybridized with the ${ }^{32} \mathrm{P}-$ labeled DNA probes. The number of bands reflects the number of transgene insertions. A, ZmPR4:gus plants (lines R32-17, R32-2, and R32-14 lines) and control Senia plants (SC). The ZmPR4 promoter sequence was used as the hybridization probe. B, mpi:gus plants (lines M17-8, M16-4) and control Senia plants (SC). The gus gene was used as the hybridization probe. $\mathrm{B}=$ Bam $\mathrm{HI}, \mathrm{E}=$ EcoRI, $\mathrm{H}=H$ indIII, and $\mathrm{P}=$ Pst $\mathrm{I}$. 


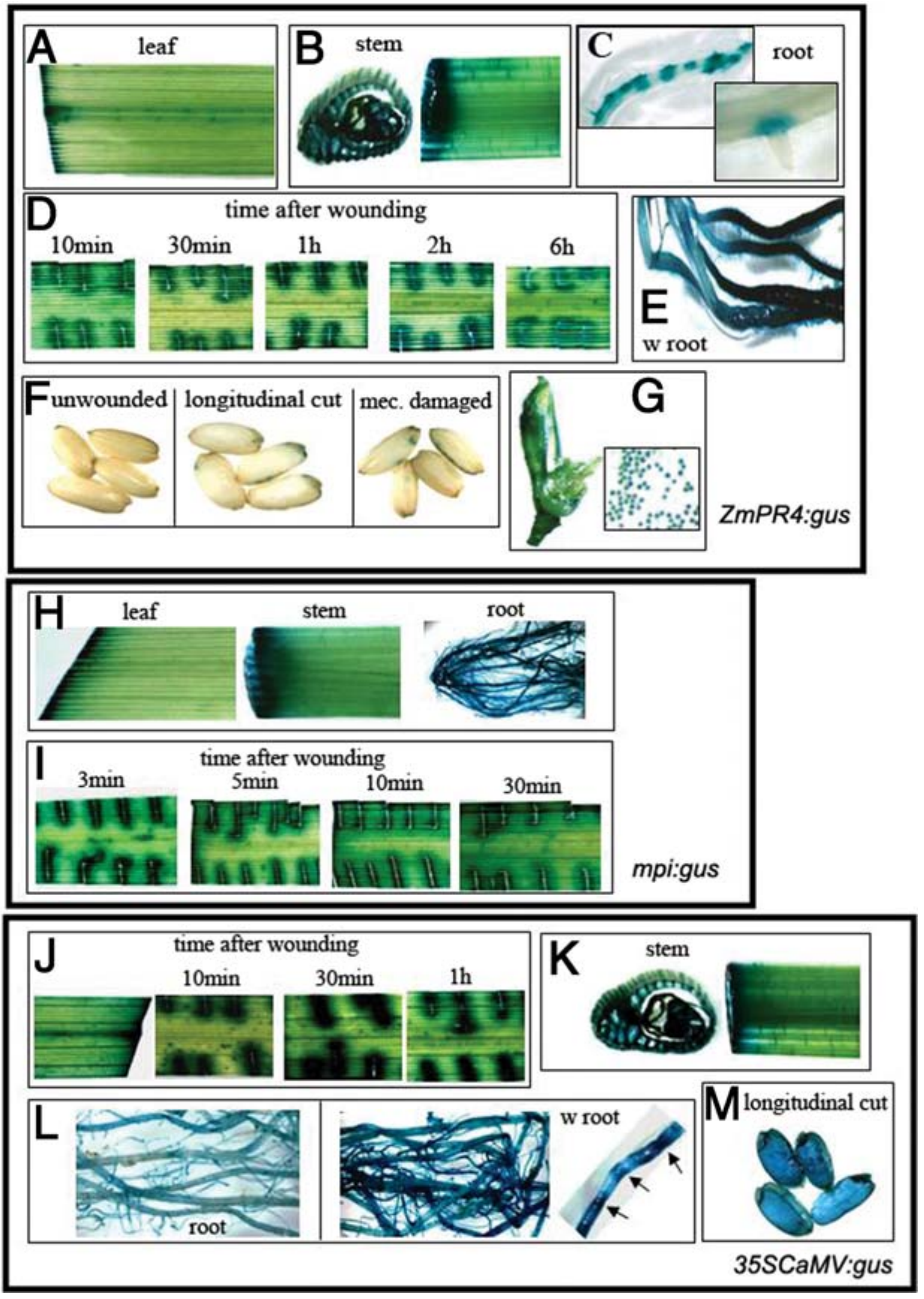

Fig. 3. Histochemical localization of $\beta$-glucuronidase (GUS) activity in representative transgenic rice plants containing promoter:gus constructs. The GUS expression patterns directed by the ZmPR4, mpi, and 35SCaMV promoters are shown. A through G, Representative examples of the pattern of GUS expression in vegetative and reproductive tissues of rice plants harboring the ZmPR4:gus (T2 homozygous lines). A, Leaf, B, stem; C, root (inset, site of lateral root emergence); D, wounded leaf; E, wounded roots; F, seeds (unwounded, longitudinally cut, and mechanically damaged); and $\mathbf{G}$, flowers (inset, pollen grains). $\mathbf{H}$ and $\mathbf{I}$, Histochemical analysis of expression of the mpi:gus fusion in tissues of transgenic rice plants. $\mathbf{H}$, Leaf, stem, and roots; and $\mathbf{I}$, wounded leaf. $\mathbf{J}$ through $\mathbf{M}$, Histochemical analysis of expression of the 35SCaMV:gus fusion in tissues of transgenic rice plants. J, Wounded leaf; $\mathbf{K}$, stem; $\mathbf{L}$, root (left panel) and wounded root (right panel) (arrows denote sites of injury), and $\mathbf{M}$, seeds (longitudinally cut). 
The activity of the ZmPR4 promoter in floral tissues of transgenic rice is presented in Figure 3G. In mature flowers of ZmPR4:gus transformants, GUS staining was observed in the lemma and palea. No activity was detected in the pedicel, ovaries, stigma, style, and anthers, but pollen collected from anthers stained blue. The expression of GUS activity conferred by the ZmPR4 promoter in floral tissues might well reflect a developmentally regulated pattern of expression. It is wellknown that $P R$ genes are expressed in an organ-specific manner in uninfected plants (Constabel and Brisson 1995; Zhu et al. 1993). Particularly, developmentally regulated $P R$ gene expression in tobacco flowers is well documented (Lotan et al. 1989).

Results obtained on the histochemical localization of GUS activity in mpi:gus lines are presented in Figure $3 \mathrm{H}$ and $\mathrm{I}$. Leaves and stems of mpi:gus lines also manifested intense GUS activity at the cutting sites, whereas a generalized GUS staining was observed in the root system (unwounded roots) of mpi:gus plants (Fig. 3H). Wound-induced GUS activity in leaves of mpi:gus plants was very rapid, GUS staining being clearly observed as early as $3 \mathrm{~min}$ after wounding (Fig. 3I). Thus, wound-inducible expression of GUS activity was detected earlier in mpi:gus lines than in ZmPR4:gus plants (GUS activity became significant at $10 \mathrm{~min}$ after wounding in ZmPR4:gus plants [Fig. 3D]). Finally, GUS activity was not observed either in the seed endosperm or in pollen of mpi:gus lines (results not shown; however, the same results were previously reported for the -689 to $+197 \mathrm{mpi}$ promoter fragment [Breitler et al. 2001]).

Histochemical analysis of GUS activity in vegetative tissues of PRms:gus lines was also carried out. GUS activity was never detected either in leaves or in roots, not even under a wound regime in tissues of PRms:gus rice plants (results not shown). Whereas PRms gene expression occurs in seed tissues of maize plants (Casacuberta et al. 1991), no activity of the PRms promoter was detected in seed tissues of PRms:gus lines (results not shown).

During the course of this work, rice plants transformed with the 35SCaMV:gus gene fusion were also analyzed for GUS activity (Fig. 3J to M). Histochemical analysis of GUS activity of $35 S C a M V$ : gus lines resulted in a faint staining pattern over the entire surface of the leaf. Besides its moderate constitutive activity, intense wound-inducible GUS expression driven by the $35 S C a M V$ promoter could be detected in leaves (Fig. 3J) and stems (Fig. 3K) of the 35SCaMV:gus transformants. In unwounded roots of these lines, constitutive activity was also detected (Fig. 3L, left panel). More intense staining was, however, observed in wounded roots of 35SCaMV:gus lines, injured sites staining the most intensively of any other region of the root (Fig. 3L, right panel).

\section{The $Z m P R 4$ and mpi promoters are highly responsive to fungal infection in transgenic rice.}

To test the activity of the maize promoters in response to fungal infection, leaves of T2 homozygous rice plants containing the ZmPR4-, mpi-, or the PRms-gus fusions were inoculated with spores of the fungal pathogen $M$. grisea. The detached leaf assay described by Coca and associates (2004) was used for this study. Figure 4A shows representative examples of the results obtained in leaves of the ZmPR4:gus lines. Two to three days after inoculation, local lesions could be visualized at the infected regions of the leaves. Under noninduced conditions, the transgene was silent and no GUS activity could be detected in the leaf blade of the ZmPR4:gus transgenic rice plants (untreated leaf in Fig. 4A). In infected leaves, a highly localized pattern of GUS expression at the periphery of the developing lesions was evident. GUS activity was visible in a region 0.8 to $1.2 \mathrm{~mm}$ from the edge of the necrotic lesion and surrounding the site of infection. Trypan blue staining and microscopical observation of the $M$. grisea-infected leaves from ZmPR4:gus rice lines confirmed fungal development at the inoculated sites. The localization of induced GUS activity bordering the local lesions and the lack of GUS activity over the whole leaf area distant to these local lesions after prolonged incubation was a characteristic feature of the ZmPR4:gus plants.

In infection experiments, extensive damage is caused by the growing mycelium at the infected sites of the rice leaves. In order to differentiate wound response from infection, leaves from ZmPR4:gus plants were inoculated with a suspension of elicitors prepared from $M$. grisea and were maintained under the same experimental conditions as infected leaves. In elicitor-treated leaves from $\mathrm{ZmPR} 4$ : gus rice lines, distinct spots of GUS activity developing at these regions were evident (Fig. 4A, M. grisea elicitors). These discrete sites of intense GUS activity were clearly detected only in the elicitor-treated areas, being absent in regions at some distance from them. Three independent ZmPR4:gus transformants were examined, and similar staining patterns were observed in either fungal-infected or elicitor-treated leaves of all lines. GUS staining was not observed in leaves from untransformed Senia plants that had been infected with fungal spores or had been treated with fungal elicitors (Fig. 4B).

We also investigated the ability of the mpi promoter to direct fungal-inducible expression of the gus A reporter gene in transgenic rice. Histochemical analysis of GUS activity in $M$. grisea-infected and elicitor-treated leaves of mpi:gus lines are shown in Figure 4C. As it was found with ZmPR4:gus rice plants, GUS staining surrounding the developing lesions caused by $M$. grisea infection were clearly observed in leaves from mpi:gus lines. In contrast, GUS activity was never detected in leaves of mpi:gus lines that had been treated with elicitors prepared from $M$. grisea.

The PRms:gus lines were subjected to the same stress treatments as the ZmPR4:gus or the mpi:gus rice lines and were histochemically assayed for GUS activity. No activity of the PRms promoter was ever observed in leaves of PRms:gus rice plants under any of the stress treatments used in this work, infection with fungal spores or treatment with elicitors (results not shown). Thus, although extensive growth of the fungal mycelia occurred in the infected leaf, GUS activity was never detected. Equally, no response of the PRms promoter was observed in leaves of PRms:gus plants that had been treated with salicylic acid (results not shown). Finally, fungal-induced but not elicitor-induced expression of the $35 \mathrm{SCaMV}$ promoter in leaves of 35SCaMV:gus A rice was observed (Fig. 4D).

Thus, the picture obtained by histochemical analysis of GUS activity in ZmPR4:gus and mpi:gus rice is that these two maize promoters were strongly induced by both fungal infection and wounding in leaves of transgenic rice. ZmPR4 but not mpi promoter activity was detected in elicitor-treated leaves of transgenic rice.

\section{Production and molecular characterization of transgenic rice harboring the afp gene under the control of the maize $Z m P R 4$ promoter.}

The rice Senia variety used for transformation in this work was previously shown to be highly susceptible to infection by the M. grisea PR9 isolate (Coca et al. 2004). Accordingly, we investigated whether transgenic expression of the afp gene from A. giganteus under the control of a promoter specifically activated in response to $M$. grisea infection exhibited resistance against this fungal pathogen. To this end, transgenic rice lines expressing the afp gene under the control of the ZmPR4 

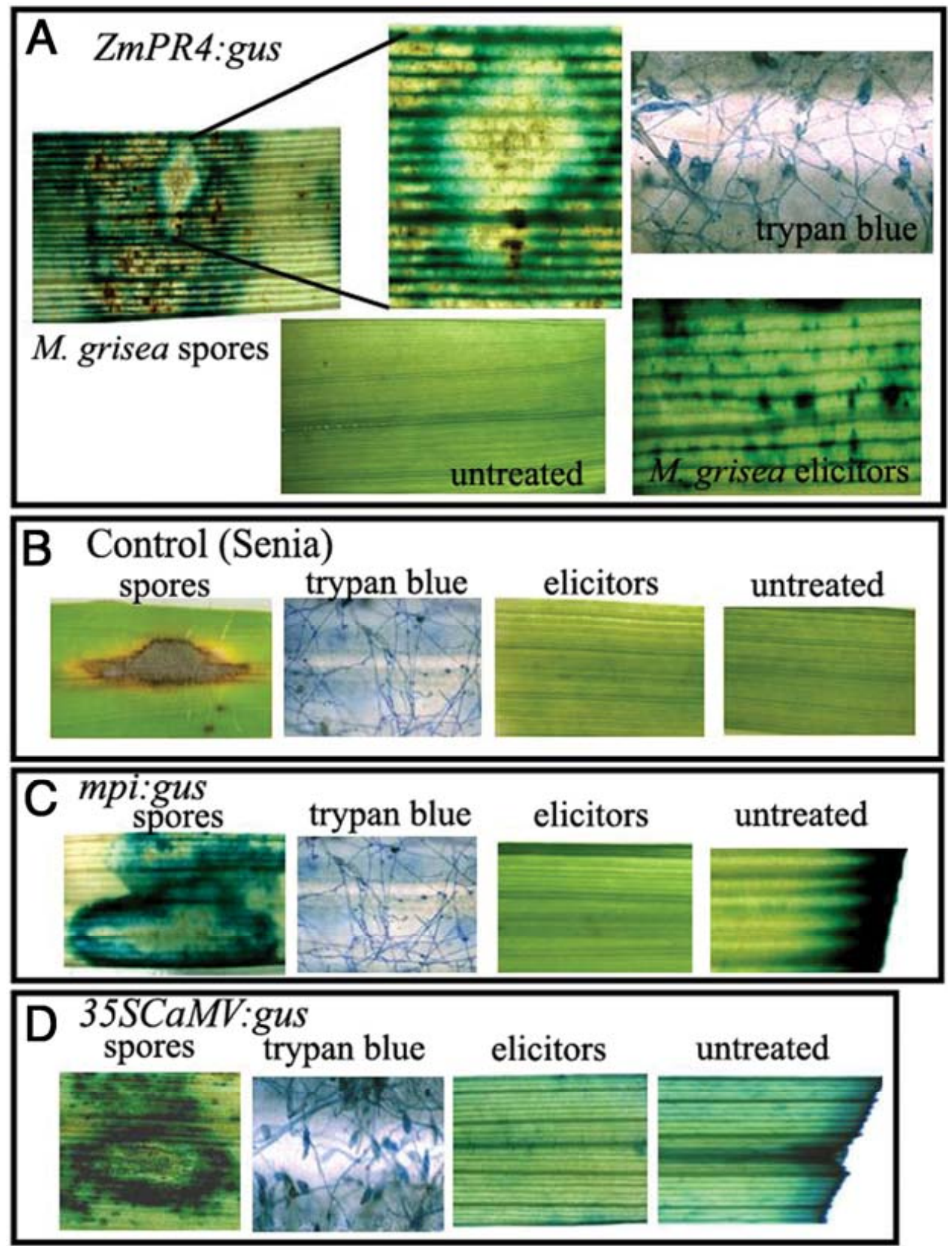

Fig. 4. Histochemical localization of $\beta$-glucuronidase (GUS) activity in leaves of transgenic rice plants after inoculation with Magnaporthe grisea spores or treatment with elicitors prepared from this fungus. A, Leaves of ZmPR4:gus rice plants were inoculated with M. grisea spores at a concentration of $10^{6}$ spores $/ \mathrm{ml}$. Three days after inoculation, leaves were histochemically stained for GUS activity or stained with trypan blue. Staining was localized to the immediate region surrounding the lesion (a close up detail of a typical blast lesion is shown). Trypan blue staining of fungus-infected leaves confirmed the presence of M. grisea growing into the leaf tissue showing GUS activity. In elicitor-treated leaves of ZmPR4:gus plants, a localized GUS activity restricted to the elicitor-treated regions was observed. As a control, leaves of ZmPR4:gus plants were inoculated with sterile water (untreated). B, Leaves of control Senia plants were inoculated with fungal spores or treated with fungal elicitors and were analyzed for GUS activity as in A. C, Histochemical analysis of expression of the mpi:gus construct in fungus-infected and elicitor-treated leaves of transgenic rice plants. Treatments were carried out as indicated in A. D, Histochemical analysis of expression of the 35SCaMV: gus construct in fungus-infected and elicitor-treated leaves of transgenic rice plants. Treatments were carried out as indicated in A. 
promoter were generated. The components of plasmid pCZmPR4::afp::nos used for rice transformation are shown in Figure 1B. A total of 21 hygromycin-resistant rice lines were regenerated and grown in the greenhouse. Transgene expression in ZmPR4:afp hygromycin-resistant T0 lines was confirmed by analyzing the wound-induced accumulation of $a f p$ mRNA (results not shown). Nine T0 ZmPR4:afp plants were selected, and T2 homozygous progeny plants were then obtained from these plants. All ZmPR4:afp rice plants were viable and displayed normal phenotype.

The copy numbers and integration patterns of the transgene were determined by genomic Southern blot. As revealed in Figure 5A, ZmPR4:afp plants showed one or two integration events (R40-6, R40-14, and R40-23 lines). The unique hybridization patterns observed indicated that each plant resulted from independent transformation events.

Fungal-induced accumulation of afp transcripts in T2 homozygous ZmPR4:afp plants was assayed by Northern blot analysis (Fig. 5B). Whereas afp transcripts were not detected in noninfected leaves, they drastically accumulated in $M$. griseainfected leaves of ZmPR4:afp lines. These results revealed that expression of the $a f p$ gene is activated in response to infection by $M$. grisea, and it is efficiently transcribed into an mRNA of the expected size in leaves of transgenic ZmPR4:afp lines.

\section{Disease resistance of $\mathrm{ZmPR} 4$ :afp rice plants.}

To examine the efficiency of the fungal-induced expression of the $a f p$ gene in rice, ZmPR4:afp lines were tested for resistance to infection with $M$. grisea. Initially, blast resistance studies were carried out on detached leaves (Fig. 6A). This approach allowed us to screen a large number of plants from five independent transformation events (lines R40-6; R40-12, R40-13, R40-14, and R40-23). At a high concentration of inoculum $\left(10^{6}\right.$ spores $\left./ \mathrm{ml}\right)$, symptoms on leaves from control plants appeared two to three days after inoculation. By this time, leaves from ZmPR4:afp plants did not exhibit blast disease symptoms (results not shown). Typical development of disease symptoms six days after inoculation of leaves from control untransformed and ZmPR4:afp Senia plants (R40-6, R40-13, and R40-23 lines) with $M$. grisea spores is presented in Figure 6A. Lesions rapidly developed in leaves of control plants. At 8 days postinoculation, leaves from control Senia plants were severely damaged or even dead. In ZmPR4:afp plants, however, small lesions were generally observed, but they either did not expand or developed much more slowly than in control plants (Fig. 6A).

We further tested the ability of ZmPR4-afp plants to block the in planta growth of $M$. grisea by counting the number of spores produced in infected leaves of control and transgenic lines. At 6 days after inoculation, the average concentration of spores collected from infected leaves of control untransformed plants was $16,560 \pm 1,240$ spores $/ \mathrm{ml}$. The concentration of spores collected from the ZmPR4:afp transgenic lines was: $1,760 \pm 140$ spores/ml for line R40-6, 1,500 \pm 150 spores $/ \mathrm{ml}$ for line R40-13, and 1,400 \pm 100 spores/ml for line R40-23 (values given represent the mean and standard error for three tallies for each infected leaf and three leaves for each transgenic line).

Next, soil-grown transgenic and control rice plants were inoculated by spraying with a $M$. grisea spore suspension. Results from these experiments show that the transgenic lines were significantly resistant to $M$. grisea infection (Fig. 6B). Control plants developed clear symptoms of infection that were observed 5 to 7 days after inoculation with fungal spores, but they were absent in ZmPR4:afp plants. Transgenic lines (lines R40-6 and R40-13) consistently performed better than controls. A strong difference in plant growth between control and transgenic rice was also observed about 3 to 4 weeks after spraying soil-grown rice plants with fungal spores. In fact, the visual differences in performance between control and transgenic plants were striking at 40 days after inoculation with $M$. grisea spores (Fig. 6B). By this time, almost all of the control plants had died and the few surviving control plants were noticeably retarded in their growth. The ZmPR4:afp lines, however, remained healthy and showed minimal leaf damage. All five ZmPR4:afp lines used in disease-resistance assays (lines R40-6, R40-12, R40-13, R40-
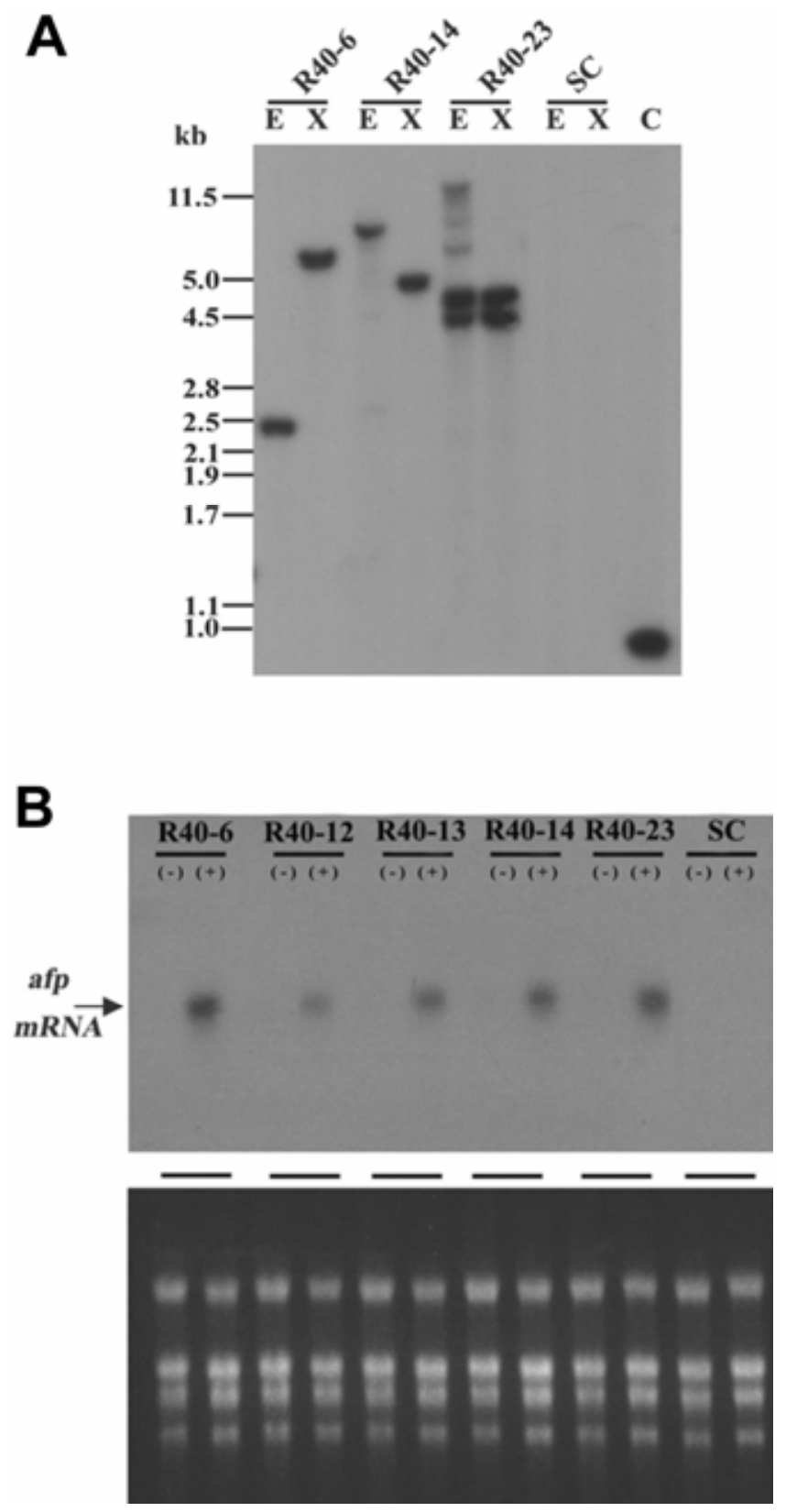

Fig. 5. Molecular analyses on transgenic ZmPR4:afp rice plants. A, Southern blot analysis of genomic DNA from leaves from homozygous T2 ZmPR4:afp (lines R40-6, R40-13, and R40-23) and control (SC) plants. Genomic DNA was digested with restriction enzymes EcoRI (E) and XbaI (X). ZmPR4 DNA was used as the probe. The number of bands reflects the number of transgene insertions. Lane C, ZmPR4 DNA. B, Northern blot analyses of RNA isolated from leaves of transgenic rice plants (lines R40-6, R40-12, R40-13, R40-14, R40-23) and control plants (SC) that were inoculated with Magnaporthe grisea spores (+). Control leaves of ZmPR4:afp plants were inoculated with water instead of the spore suspension (-). Total RNA (10 $\mu \mathrm{g})$ was probed with a ${ }^{32} \mathrm{P}$-labeled afp probe (Coca et al. 2003). The lower panel shows ethidium bromide staining of the RNA samples analyzed. 
14, and R40-23) showed similar levels of tolerance. In all the pathogen tests, control transgenic plants transformed with the empty vector (pCAMBIA 1300) showed results essentially similar to those of wild-type plants (results not shown; however, similar results were previously described by Coca and associates [2004]). Together, the results from disease-resistance assays clearly demonstrate that the pathogen-induced expression of $a f p$ confers protection to rice plants against the fungal pathogen $M$. grisea.

To substantiate the results of symptom development, we performed trypan blue staining and microscopical observations of infected leaves. In control leaves inoculated with $M$. grisea spores, extensive fungal development could be visualized, whereas under the same experimental conditions, no fungal development was observed in leaves from ZmPR4:afp lines. Trypan blue staining of representative control and ZmPR4:afp lines are presented in Figure 7. The pathogen growing in leaves of control plants was able to produce a large number of conidia (Fig. 7A, inset). In contrast, no fungal colonization was observed on the infected sites of leaves from transgenic lines (Fig. 7B and C). Only some short hyphae could be detected at the infected sites of leaves from ZmPR4:afp plants.

\begin{tabular}{|c|c|}
\hline \begin{tabular}{|l|} 
A 6 dpi \\
Senia control
\end{tabular} & 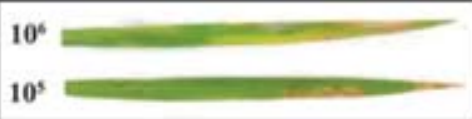 \\
\hline R40-6 & $\sqrt{2+20}$ \\
\hline R40-13 & 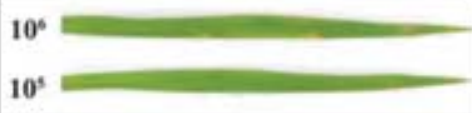 \\
\hline R40-23 & $=$ \\
\hline $\begin{array}{r}8 \text { dpi } \\
\text { Senia control }\end{array}$ & $1 0 ^ { 5 } \longdiv { \square = 0 0 }$ \\
\hline R40-6 & $10^{s}$ \\
\hline R40-13 & $10^{5}$ \\
\hline R40-23 & $10^{s}$ \\
\hline
\end{tabular}

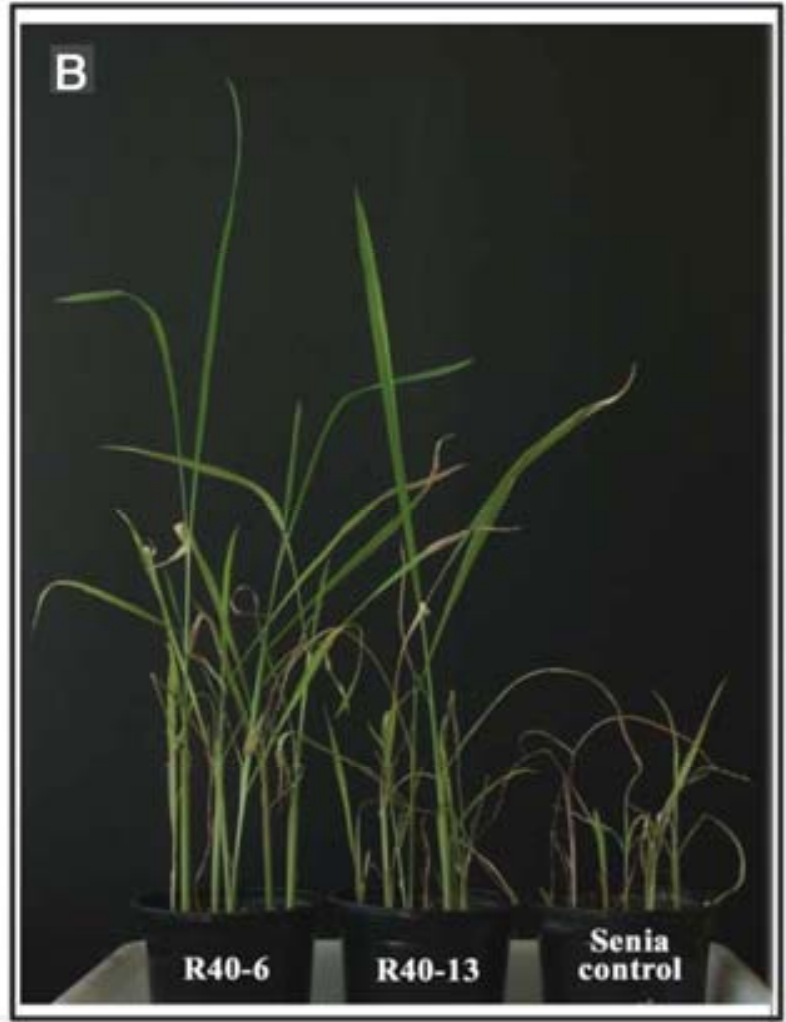

Fig. 6. Resistance in transgenic rice plants expressing the afp gene from Aspergillus giganteus under the control of the maize ZmPR4 promoter. Five independent ZmPR4:afp lines (R40-6, R40-12, R40-13, R40-14, and R40-23) were tested for blast resistance. A, Detached leaves from control untransformed Senia plants and ZmPR4:afp rice lines (T2 generation, lines R40-6, R40-13, and R40-23) were locally inoculated with Magnaporthe grisea spores. The concentration of inoculum is indicated on the left. Disease symptoms 6 and 8 days after inoculation of leaves from ZmPR4:afp plants is shown. Symptom development in ZmPR4:afp R40-12 and R40-14 lines was comparable to that shown for lines R40-6, R40-13, and R40-23. Results shown are from one of four experiments that produced similar results. B, Soil-grown ZmPR4:afp plants (lines R40-6 and R40-13) and control Senia plants at the three-leaf stage were sprayed with a suspension of $M$. grisea spores $\left(10^{4}\right.$ spores $\left./ \mathrm{ml}\right)$. Picture was taken 40 days after inoculation with fungal spores. The three other ZmPR4:afp lines (R40-12, R40-14, and R40-23) showed levels of protection comparable to those observed in the R40-6 and R40-13 lines.
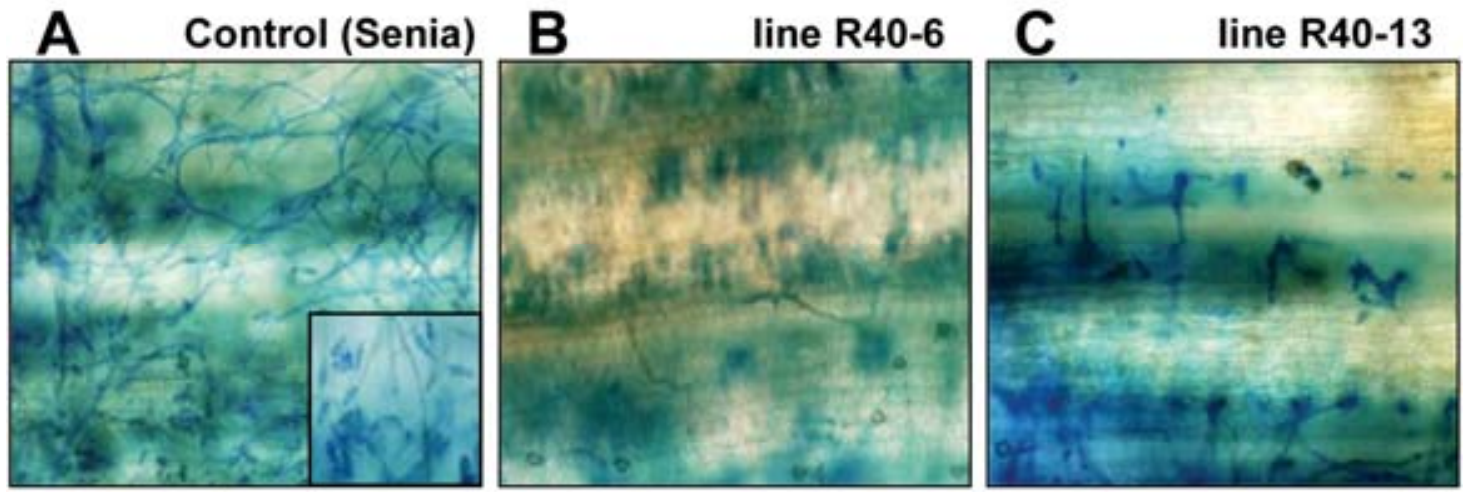

Fig. 7. Representative trypan blue staining of leaves inoculated with Magnaporthe grisea spores. Staining was carried out 6 days after inoculation with fungal spores. A, Leaves from control plants were fully colonized by mycelium and produced conidia (inset), whereas, under the same experimental conditions, no hyphae or hyphae showing abnormal morphology were detected in leaves of ZmPR4:afp plants from lines B, R40-6 and C, R40-13. 


\section{DISCUSSION}

Transformation of plants with genes of agronomic importance, such as those that confer resistance to pathogens, has been a general approach for obtaining disease-resistant plants (Datta et al. 1999). In crop plants, however, there is an increasing interest in the development of regulated expression systems in which the expression of the transgene occurs only in the presence of particular pathogens. Despite the fact that cereals, rice in particular, represent important crops in the world, relatively little work has been reported on promoters that confer regulated or tissue-specific expression of transgenes of agronomic importance in this crop species.

Here, we describe a strategy for engineering transgenic rice plants with resistance to the blast fungus $M$. grisea. The approach relies on the use of an inducible rather than a constitutive promoter to direct the site-specific expression of an antifungal gene and at a level sufficient for protecting transgenic rice plants against blast. The $a f p$ gene from A. giganteus was chosen for this work because previous studies indicated that expression of this gene under the control of the constitutive maize ubiquitin 1 promoter in transgenic rice results in enhanced resistance to $M$. grisea (Coca et al. 2004). Furthermore, a commercial rice variety ( $O$. sativa $\mathrm{L}$. cv. Senia) was used in this work.

A search for the identification of promoters driving highlevel, pathogen-inducible expression of the gus A reporter gene in stable transformed rice plants was carried out. Promoters of three $P R$ genes from another monocotyledonous species, maize, were assayed, the $Z m P R 4, m p i$, and PRms promoters. Whereas genomic clones containing the PRms and mpi sequences were already available, the genomic clone encoding the maize $Z m P R 4$ gene was isolated and characterized during the course of this work. The overall structure of the ZmPR4 gene, with a small intron interrupting the coding sequence, is similar to that reported for members of the PR-4 family of PR proteins (PR4 plant chitinases).

To examine the expression patterns of the three maize promoters in tissues of transgenic rice, ZmPR4-, mpi-, and PRmsgus gene fusions were introduced into rice. The $Z m P R 4$ and $m p i$ but not the PRms promoters appear to be active in leaves of transgenic rice. Both the ZmPR4 and mpi promoter confer fungal-inducible expression to the gus $A$ reporter gene. The activation of the $Z m P R 4$ and $m p i$ promoters in response to blast infection is highly localized, occurring exclusively in regions surrounding blast infection sites. In addition to its fungal-inducibility, the $\mathrm{ZmPR} 4$ promoter region is activated in response to treatment with fungal elicitors. Contrary to this, the mpi promoter showed no responsiveness to treatment with fungal elicitors. The elicitor-responsiveness observed for the $Z m P R 4$ promoter suggests that this promoter responds to on or more molecules of fungal origin during the rice- $M$. grisea interaction. One key question that remains to be elucidated is the biochemical nature of the one or more active molecules present in the elicitor preparation from $M$. grisea responsible for the elicitor-induced response of the $Z m P R 4$ promoter.

The two maize promoters, $Z m P R 4$ and $m p i$, also direct local wound-inducible expression of the gus reporter gene in transgenic rice. In this respect, it is well-known that infection of plant tissues not only activates specific pathogen-inducible defense responses to prevent pathogen infection but, in addition, wound-inducible responses (Rushton et al. 2002). Most probably, convergence occurs in the response of the ZmPR4 promoter to $M$. grisea infection; this response being the consequence of both the molecular recognition of the pathogen (elicitor-inducibility) and the wound produced by the penetration and colonization of the host tissues by the pathogen (wound-inducibility).
Activation of the mpi promoter, however, would be more the direct response to the wound produced by fungal colonization of leaf tissues (wound-inducibility) but not to the molecular recognition of the pathogen (no elicitor-inducibility of the $m p i$ promoter). Further studies are required to clarify these aspects.

Together, results here presented on the functional analysis of the maize $Z m P R 4$ and $m p i$ promoters in stable transformed rice plants indicated that the typical features of stress-inducibility of these promoters are conserved among maize and rice plants. Particularly, the fungal- and elicitor- as well as woundresponsiveness of the ZmPR4 promoter were faithfully reproduced in transgenic rice plants. The mpi promoter proved responsiveness to fungal infection and wounding but not to treatment with fungal elicitors in transgenic rice, as is also observed in maize plants.

On the other hand, a number of well recognized cis-regulatory elements that are known to be involved in the pathogenor elicitor-activated gene expression were identified in the maize promoter fragments assayed in this work. In agreement with its elicitor-responsiveness, a W box (TTTGACT at position -864) and an ERE motif (ATTGACG at position -285) are present within the ZmPR4 promoter region. The mpi promoter fragment contains two $\mathrm{W}$ boxes (CTTGACTT and CTTGACC, at positions $-1,471$ and -786 , respectively). The lack of elicitor-responsiveness of the mpi promoter, however, suggests that none of these potential cis-regulatory elements is functional in elicitor-treated leaves of mpi:gus rice plants. In addition, several regulatory elements involved in the woundinducible expression of different genes were also found in the ZmPR4 and mpi promoters. Further experiments are needed to elucidate which of the cis-elements identified in these promoters is responsible for their pathogen-, elicitor-, and woundinducibility in transgenic rice. Finally, even though an ERE motif (AATTGACC, at position -246) is found in the PRms promoter, neither infection with fungal spores nor treatment with fungal elicitors activated this promoter in leaves of transgenic rice.

In this work, the CaMV35S promoter, one of the most common promoters used to drive constitutive expression of transgenes in stable transgenic events, was found to be activated in response to wounding and infection with fungal spores but not in response to treatment with fungal elicitors. A number of reports in the literature support the stress inducibility of the CaMV35S promoter in transgenic plants (Ruiz-Rivero and Prat 1998; Xiang et al. 1996). Moreover, several cis-element motifs that are known to be involved in wound-induced expression of plant genes, such as the $a s-1$ element or the CGTCA motifs, are present in the $35 S C a M V$ promoter fragment used in this work (Jupin and Chua 1996; Xiang et al. 1996). The information presented in this report on the wound- and fungal-inducibility of the $35 S C a M V$ promoter will be useful for both basic and applied studies involving 35SCaMV promoter-mediated transgene expression in rice plants.

Of particular interest is the finding that GUS reporter gene expression was not detected in the endosperm of seeds produced by ZmPR4:gus rice lines. This property of the promoter is important in cases where promoter activity in the edible part of a plant, such as the rice endosperm, is not desired. Together, the strong induction of GUS expression at the sites of pathogen infection and elicitor-treated regions of leaves in combination with the observation that no activity of the $Z m P R 4$ promoter is detected in the endosperm revealed the $Z m P R 4$ promoter as a suitable promoter to drive expression of an antifungal gene in transgenic rice. Accordingly, transgenic rice plants harboring a fusion between the ZmPR4 promoter and the afp gene were generated. Northern blot analysis of leaves from ZmPR4:afp rice plants that had or had not been infected with fungal spores 
confirmed that the ZmPR4 promoter is specifically activated after $M$. grisea infection. Most importantly, results here presented indicate that the in planta pathogen-induced production of AFP occurs at levels sufficient for protecting rice plants against blast. Under controlled greenhouse conditions, protection was observed even when high concentrations of inoculum are used in infection experiments $\left(10^{6}\right.$ spores $\left./ \mathrm{ml}\right)$. Presumably, the delay in the appearance of symptoms as well as the lower severity of disease may enable rice plants to overcome natural blast infection under field conditions. Resistance of the ZmPR4:afp transgenic plants against rice blast needs now to be confirmed by further evaluation in the field.

To conclude, the fungal-induced expression of afp gene represents an alternative to the economically costly, health-harmful, and environmentally undesirable chemical control of the rice blast fungus $M$. grisea. Furthermore, the availability of a fungal- and elicitor-inducible promoter such as the ZmPR4 promoter would be extremely valuable to drive expression of other antifungal genes in tissues of the transgenic rice while no accumulation of their corresponding transgene products in the endosperm, the organ destined to human consumption, is expected.

\section{MATERIALS AND METHODS}

Plant and fungal materials.

The commercial japonica rice (Oryza sativa L. cv. Senia) was used. The Magnaporthe grisea PR9 isolate was provided by D. Tharreau, CIRAD-Montpellier (France). This isolate was previously shown to be highly virulent to the rice cultivar Senia used in this work (Coca et al. 2004). The fungus was grown on rice-agar plates $(20 \mathrm{~g}$ of rice flour, $2.5 \mathrm{~g}$ of yeast extract, and $15 \mathrm{~g}$ of agar per liter, containing $0.03 \mu \mathrm{g}$ of chloramphenicol per microliter) at $28^{\circ} \mathrm{C}$, until the mycelium had covered the surface of the plate. Fungal spores were collected by adding sterile water to the surface of the mycelium; suspensions were filtered and microscopically examined. The spore suspension was adjusted to the appropriate final concentration, using a Bürker counting chamber. For preparation of fungal elicitors, $M$. grisea was grown in liquid medium for approximately four weeks. Fungal mycelium was collected by filtering the fungal culture and used for preparation of crude elicitors as previously described (Casacuberta et al. 1992).

\section{Isolation of the $\mathrm{ZmPR} 4$ genomic clone and DNA sequence analysis.}

Screening of an EMBL3 genomic library from Zea mays (B73 variety; Clontech, Palo Alto, CA, U.S.A.) was performed. The isolated cDNA insert from the ZmPR4 cDNA clone described by Bravo and associates (2003) was used as the hybridization probe.

Sequencing was performed with the Terminator cycle sequencing ready reaction kit (Perkin Elmer Corp., Norwalk, CT, U.S.A.), using the universal vector primers or specific internal primers. The sequencing reactions were visualized and processed with ABIPRISM377. The location and distribution of cis-regulatory sequence elements in the ZmPR4 promoter region were analyzed in the Plant Care database.

\section{Construction of plant transformation vectors.}

Constructs used for Agrobacterium-mediated transformation of rice were all based on the pCAMBIA plasmid vector (CAMBIA, Canberra, Australia). Promoter-gusA gene fusions were prepared to determine the activity of the $Z m P R 4, m p i$, and PRms promoters in transgenic rice. To prepare the ZmPR4:gus construct, a DNA fragment covering 1,450 bp of the promoter and the $81 \mathrm{bp}$ of the $5^{\prime}$ untranslated region of the
$Z m P R 4$ gene was generated by the polymerase chain reaction (PCR) from the genomic ZmPR4 genomic clone and primers R15 (5'-CTCCCCGGGCTCGATGCTTCGCCGTATC-3') and R14 (5'-CTCAAGCTTGGCAACCGATCGATGTAG-3') (underlined sequences indicate SmaI and HindIII restriction sites introduced in the PCR primers to facilitate subsequent cloning steps). The $-1,450$ to $+81 \mathrm{ZmPR} 4$ promoter fragment was inserted into the SmaI-HindIII-digested pCAMBIA1381-Z vector containing the Escherichia coli gus A gene to obtain the pCZmPR4::gus::nos construct (Fig. 1B).

To prepare the mpi:gus gene fusion, a ScaI/NruI DNA fragment was excised from the $\lambda 35 \mathrm{mpi}$ genomic clone described by Cordero and associates (1994b). This DNA fragment contained $1,872 \mathrm{bp}$ of the mpi promoter and the $197 \mathrm{bp}$ of the 5' untranslated sequence of the mpi gene, including the intron of $108 \mathrm{bp}$ that is present in the $5^{\prime}$ untranslated sequence. The $-1,872$ to +197 mpi promoter fragment was cloned into the C90:gus:nos plasmid (a pBluescript-derived plasmid containing the gus A reporter gene and nos terminator) to obtain the $\mathrm{pBmpi}:$ gus:: nos construct (Fig. 1B). For functional analysis of the PRms promoter, the -736 to +53 region of the PRms gene described by Casacuberta and associates (1991) was cloned into the C90::gus::nos plasmid to obtain the pBPRms::gus::nos construct (Fig. 1B).

A pCAMBIA-derived plasmid containing the A. giganteus afp gene under the control of the $-1,450$ to +81 ZmPR4 promoter and the nos terminator was prepared. The quimeric synthetic afp gene described by Coca and associates (2004), in which the nucleotide sequence coding for the signal peptide of the AP24 protein from tobacco is fused to a codon-optimized sequence of the mature AFP protein, was used to transform rice plants. Initially, the $-1,450$ to $+81 \mathrm{ZmPR} 4$ promoter fragment was inserted into the HindIII/SmaI sites of the pBSK plasmid ( $p B:: Z m P R 4$ construct). On the other hand, the DNA fragment containing the coding sequence of the synthetic afp gene and the nos terminator was PCR-amplified from the pCubi::synt-afp::nos plasmid (Coca et al. 2004). Appropriate restriction sites were introduced into the PCR-amplified DNA suitable for the subsequent cloning steps (SmaI at the 5' end; EcoRI and HindIII at the $3^{\prime}$ end). The PCR-amplified afp:nos DNA was then cloned into the SmaI/EcoRI-digested $p B:: Z m P R 4$. In this way, a pBSK-derived plasmid containing the cassette for expression of the afp gene under the control of the $Z m P R 4$ promoter was obtained. Finally, the entire cassette (ZmPR4::afp::nos) was excised from this plasmid by digestion with HindIII and was inserted into the HindIII-digested pCAMBIA1300, to obtain the pCZmPR4::afp::nos construct (plasmid for fungal-inducible expression of the afp gene) (Fig. 1B).

DNA manipulations and transformation of E. coli (strain DH5 $\alpha$ ) with plasmid DNA were performed according to standard protocols (Sambrook et al. 2001). Constructs used for rice transformation were verified by nucleotide sequencing. The pCZmPR4::gus::nos and pCZmPR4::afp::nos constructs were transferred to A. tumefaciens EAH105 (Hood et al. 1993).

\section{Production of transgenic rice plants.}

Embryonic callus derived from mature embryos of the rice cultivar Senia were used as the target tissue for transformation. Transgenic plants were generated either by Agrobacteriummediated transformation ( $p C Z m P R 4:: g u s:: n o s$ and $p C:: Z m P R 4:$ : afp::nos rice plants) (Pons et al. 2000) or through particle bombardment (pBmpi::gus::nos or $\mathrm{pBPRms::gus::nos}$ rice plants) (Chen et al. 1998). Transgenic rice plants harboring the pCAMBIA 1301 vector containing the gus A gene fused to the CaMV35S promoter and the nos terminator were also produced and used as a positive control for expression of the gus 
gene. The pCAMBIA vectors used in this work (pCAMBIA 1381Z, 1300, and 1301) already had the hptII (hygromycin phosphotransferase) gene encoding hygromycin resistance in the T-DNA region. The pIILTAB227 construct (Chen et al. 1998) carrying the hygromycin phosphotransferase hpt gene under the control of the $C a M V 35 S$ promoter with a duplicated enhancer region was used as the co-introduced selectable construct in experiments by biolistic transformation. Selected T0 plants were cultivated in greenhouse conditions at $27 \pm 2{ }^{\circ} \mathrm{C}$ under an 18-h light and 6-h dark photoperiod to obtain homozygous transgenic lines in the $\mathrm{T} 2$ generation.

\section{DNA isolation and Southern blot analysis.}

DNA was extracted according to the method of Murray and Thompson (1980) but using MATAB (mixed alkyltrimethylammonium) (0.1 M Tris $\mathrm{HCl}, \mathrm{pH} 8.0,1.4 \mathrm{M} \mathrm{NaCl}, 20 \mathrm{mM}$ EDTA, 2\% MATAB, $1 \%$ polyethylene glycol 6000, $0.5 \%$ sodium sulphite) as the extraction buffer. Appropriate enzymes were used to estimate transgene copy number. DNAs were electrophoresed on $0.8 \%$ agarose gels, were transferred to $\mathrm{Hy}$ bond-N membranes (Amersham Biosciences, Piscataway, NJ, U.S.A.), were and hybridized to ${ }^{32}$ P-labeled DNA probes. The DNA probes were labeled by random priming (Roche Diagnostics $\mathrm{GmbH}$, Mannheim, Germany). Hybridization was carried out in $50 \mathrm{mM}$ Tris $\mathrm{HCl}, \mathrm{pH} 8.0,10 \mathrm{mM}$ EDTA, 5× SSC ( $1 \times \mathrm{SSC}$ is $0.15 \mathrm{M} \mathrm{NaCl}$ plus $0.015 \mathrm{M}$ sodium citrate), $1 \times$ Denhardt's reagent, $0.2 \%$ sodium dodecyl sulfate (SDS), $10 \%$ dextran sulphate containing $100 \mu \mathrm{g}$ of salmon sperm DNA per milliliter at $65^{\circ} \mathrm{C}$. Membranes were washed to $0.1 \times \mathrm{SSC}, 0.1 \%$ SDS at $65^{\circ} \mathrm{C}$.

\section{RNA isolation and Northern blot analysis.}

Total RNA was isolated from the leaves of transgenic and control plants as described by Logeman and associates (1987). RNAs were subjected to formaldehyde-containing agarose gel electrophoresis and were transferred to nylon membranes (Hybond-N; Amersham). All probes were gel-purified and radioactively labeled by random priming, according to the manufacturer's protocol (Roche). Hybridizations were performed in $40 \%$ formamide, $5 \times$ SSPE $(1 \times \mathrm{SSPE}$ is $0.18 \mathrm{M} \mathrm{NaCl}, 10 \mathrm{mM}$ $\mathrm{NaPO}_{4}$, and 2 mM EDTA [pH 7.7]), 0.5\% SDS, $5 \times$ Denhardt's reagent containing $100 \mu \mathrm{g}$ of salmon sperm DNA per milliliter, at $42^{\circ} \mathrm{C}$. Membranes were washed to $3 \times \mathrm{SSC}, 0.5 \% \mathrm{SDS}$ at $65^{\circ} \mathrm{C}$.

\section{Histochemical localization of GUS expression.}

Tissues of the rice plants were histochemically assayed for GUS activity as described by Jefferson and associates (1987), using the chromogenic substrate 5-bromo-4-chlore-3-indolyl$\beta$-D-glucuronide (X-gluc; Sigma, St. Louis). Tissues were submitted to vacuum infiltration for $20 \mathrm{~min}$ in the $\mathrm{X}$-gluc solution and then were incubated at $37^{\circ} \mathrm{C}$ for 18 (leaves, stems, seeds, flowers) or $4 \mathrm{~h}$ (roots), in the dark. Tissues were cleared by successive washes in $70 \%$ ethanol. Experiments to localize GUS expression in tissues of the various transgenic lines assayed in this work, including the 35SCaMV:gus rice lines, were carried out at least three times for each line and for three independent lines with each construct.

\section{Fungal infection and treatments of rice plants.}

Experiments of fungal infection with $M$. grisea were carried out using the detached leaf assay described by Coca and associates (2004). Briefly, the second leaf of 2-week-old soilgrown rice plants were placed into plate dishes with $1 \% \mathrm{wt} / \mathrm{vol}$ water agar containing $2 \mathrm{mg}$ of kinetine per liter. Whatman filter paper disks saturated with a $M$. grisea PR9 spore suspension at the appropriate concentration were placed onto the upper face of the leaf for $48 \mathrm{~h}$ and then were removed. The inoculated leaves were maintained in chamber under humid conditions at $28^{\circ} \mathrm{C}$ under a 16-h light and 8-h dark cycle for the required time.

Trypan blue staining was used to confirm fungal colonization. For this, the fungal-inoculated leaves were fixed by vacuum infiltration for $1 \mathrm{~h}$ at room temperature with formaldehyde (ethanol/formaldehyde/acetic acid, 80:3.5:5 vol/vol/vol). After one change, the tissue was kept in the fixation solution overnight. The plant material was then stained with lactophenol blue solution for $6 \mathrm{~h}$ at room temperature, was washed with water, and was observed with a Zeiss Axiophot microscope (Carl Zeiss, Thornwood, NY, U.S.A.) under bright-field illumination.

Treatment of leaves with fungal elicitors was carried out in detached leaves using sterile filter paper disks embedded in an elicitor suspension at a concentration of $300 \mu \mathrm{g} / \mathrm{ml}$ (dry weight of elicitor per milliliter of water). Controls were treated with sterile water.

To investigate the wound response, leaves of soil-grown plants at the four-leaf stage were wounded, making small perpendicular cuts along both edges of the leaf blade. Wounded tissues were sampled at different times after wounding and were analyzed for GUS activity. Mature leaves of transgenic rice plants were also mechanically wounded and were analyzed for GUS activity. Mature seeds were longitudinally cut with a scalpel and were brushed with sand paper or mechanically wounded before GUS histochemical assays. All experiments were carried out at least three times to confirm the reproducibility of the results.

\section{Blast resistance studies.}

To test resistance to $M$. grisea infection of transgenic plants harboring the afp gene under the control of the pathogeninducible $Z m P R 4$ promoter, detached leaves were inoculated with different doses of $M$. grisea spores as described above. Development of disease symptoms over time was followed. Five independent ZmPR4:afp lines and three rice lines transformed with the empty vector and at least five plants for each line were assayed. Furthermore, the ability of the fungus to grow and produce spores was estimated by counting the number of spores collected from control and transgenic rice lines. Infection with $M$. grisea spores was accomplished, using the detached leaf assay with a spore suspension at a concentration of $1 \times 10^{6}$ spores $/ \mathrm{ml}$ and five inoculations per leaf. Spores were harvested from each leaf in $1 \mathrm{ml}$ of sterile water. The infection was quantified six days after infection, using a Bürker counting chamber to count a $10-\mu l$ aliquot of each sample. Three independent counts from each sample and from three individual leaves for each independent transgenic line (lines R40-6, R40-13, and R40-23) were averaged to calculate the number of spores per milliliter.

Finally, evaluation of resistance to blast of ZmPR4:gus rice plants was assayed by spraying soil-grown control and transgenic rice plants with $M$. grisea spores. Plants at the three-leaf stage were sprayed with a spore suspension $\left(10^{4}\right.$ spores $/ \mathrm{ml}$, containing $0.02 \%$ [vol/vol] Tween 20 ) until leaves were covered with fine droplets. Following inoculation, the plants were maintained in a dew chamber with $95 \%$ relative humidity at $27 \pm 2{ }^{\circ} \mathrm{C}$ under a 18-h light and 6-h dark photoperiod. Development of symptoms was monitored visually.

\section{ACKNOWLEDGMENTS}

G. Peñas is a recipient of a predoctoral fellowship from the Generalitat de Catalunya. We thank D. Tharreau for providing us with the $M$. grisea PR9 isolate and for his continuous support and advice on blast resistance studies. 
We are also grateful to P. Fontanet for taking care of the greenhouse plants, to A. Sánchez for assistance in figure preparation, and to E. Illa for technical assistance. This research was supported by the European Commission (QLRT-CT99-1484, EURICE) and by the Ministerio de Ciencia y Tecnologia (BIO2003-04936-C02). The mpi:gus rice plants were generated in the framework of the ERRI (Engineering Rice for Resistance to Insects) project from the European Commission (FAIR-CT97-3761). We also thank the Centre de Referència en Biotecnología (CeRBa) for substantial support.

\section{LITERATURE CITED}

Bravo, J. M., Campo, S., Murillo, I., Coca, M., and San Segundo, B. 2003. A maize gene encoding a class II chitinase of the pathogenesis-related protein 4 (PR-4) family exhibits activation following fungal infection and wounding. Plant Mol. Biol. 52:745-759.

Breitler, J. C., Cordero, M. J., Royer, J., Meynard, D., San Segundo, B., and Guiderdoni, E. 2001. The $-689 /+197$ region of the maize protease inhibitor gene directs high level, wound-inducible expression of the Cry $1 B$ gene which protects transgenic rice plants from stemborer attack. Mol. Breeding 7:259-274.

Campo, S., Carrascal, M., Coca, M., Abián, J. and San Segundo, B. 2004. The defense response of germinating maize embryos against fungal infection: A proteomics approach. Proteomics 4:383-396.

Casacuberta, J. M., Puigdoménech, P., and San Segundo, B. 1991. A gene coding for a basic pathogenesis-related (PR-like) protein from Zea mays. Molecular cloning and induction by a fungus (Fusarium moniliforme) in germinating maize seeds. Plant Mol. Biol. 16:527-536.

Casacuberta, J. M., Raventós, D., Puigdoménech, P., and San Segundo, B. 1992. Expression of the gene encoding the PR-like proteins PRms in germinating maize embryos. Mol. Gen. Gen. 234:97-104.

Coca, M., Bortolotti, C., Rufat, M., Peñas, G., Eritja, R., Tharreau, D., Martinez del Pozo, A., Messeguer, J., and San Segundo, B. 2004. Transgenic rice plants expressing the antifungal AFP protein from Aspergillus giganteus show enhanced resistance to the rice blast fungus Magnaporthe grisea. Plant Mol. Biol. 54:245-259.

Constabel, C. P., and Brisson, N. 1995. Stigma- and vascular-specific expression of the PR-10a gene of potato: A novel pattern of expression of a pathogenesis-related gene. Mol. Plant-Microbe Interact. 8:104-113.

Cordero, M. J., Raventós, D., and San Segundo, B. 1994a. Expression of a maize proteinase inhibitor gene is induced in response to wounding and fungal infection: Systemic wound-response of a monocot gene. Plant J. 6:141-150.

Cordero, M. J., Murillo, I., Arroyo, D., Eritja, R., and San Segundo, B. 1994b. Use of oligonucleotide-alkaline phosphatase conjugates as nonradioactive probes for rapid analysis of a proteinase inhibitor gene from Zea mays. Plant Mol. Biol. Rep. 12:265-273.

Chen, L., Zhang, S., Beachy, R. N., and Fauquet, C. M. 1998. A protocol for consistent, large scale production of fertile transgenic rice plants. Plant Cell Rep. 18:25-31.

Dangl J. L., and Jones, J. D. 2001. Plant pathogens and integrated defense responses to infection. Nature 411:826-833.

Datta, S., Muthukrisnan, S., and Datta, S. K. 1999. Expression and function of PR proteins in transgenic plants. Pages 261-277 in: Pathogenesis-Related Proteins in Plants, S. K. Datta and S. Muthudrishan, eds. CRC Press, New York.

Epple, P., Apel, K., and Bohlmann, H. 1997. Overexpression of an endogenous thionin enhances resistance of Arabidopsis against Fusarium oxysporum. Plant Cell 9:509-520.

Eulgem T., Rushton, P. J., Robatzek, S., and Somssich, I. E. 2000. The WRKY superfamily of plant transcription factors. Trends Plant Sci. 5:199-206.

Gao, A.-G., Hakimi, S. M., Mittanck, C. A., Wu, Y., Woerner, M. M., Stark, D. M., Shah, D. M., Liang, J., and Rommens, C. M. 2000. Fungal pathogen protection in potato by expression of a plant defensin peptide. Nat. Biotechnol. 18:1307-11310.

Hood, E. E., Gelvin, S. B., Melchers, L. S., and Hoekema, A. 1993. New Agrobacterium helper plasmids for gene transfer to plants. Transgenic Res. 2:208-218.

Jefferson, R. A., Kavanagh, T. A., and Bevan, M. W. 1987. GUS fusions: $\beta$-Glucuronidase as a sensitive and versatile gene fusion marker in higher plants. EMBO J. 6:3901-3907.

Joshi, C. P. 1987. An inspection of the domain between putative TATA box and translation start site in 79 plant genes. Nucleic Acid. Res. 15:66436653.

Jupin, I., and Chua, N. H. 1996. Activation of the CaMV as-1 cis-element by salicylic acid: Differential DNA-binding of a factor related to
TGA1a. EMBO (Eur. Mol. Biol. Organ.) J. 15:5679-5689.

Kanzaki, H., Nirasawa, S., Saitoh, H., Ito, M., Nishihara, M., Terauchi, R., and Nakamura, I. 2002. Overexpression of the wasabi defensin gene confers enhanced resistance to blast fungus (Magnaporthe grisea) in transgenic rice. Theor. Appl. Genet. 105:809-814.

Lacadena, J., Martínez del Pozo, A., Gasset, M., Patiño, B., CamposOlivas, R., Vázquez, C., Martínez-Ruiz, A., Mancheño, J. M., Oñaderra M., and Gavilanes, J. G. 1995. Characterization of the antifungal protein secreted by the mold Aspergillus giganteus. Arch. Biochem. Biophys. 324:237-281.

Lebel, E., Heifetz, P., Thorne, L., Uknes, S., Ryals, J., and Ward, E. 1998. Functional analysis of the regulatory sequences controlling $P R-1$ gene expression in Arabidopsis. Plant J. 16:223-233

Logeman, J., Schell, J., and Willmitzer, L. 1987. Improved method for the isolation of RNA from plant tissues. Anal. Biochem. 163:16-20.

Lorito, M., Woo, S. L., García-Fernandez, I., Colucci, G., Harman, G. E., Pintor-Toro, J. A., Filippone, E., Muccifora, S., Lawrence, C. B., Zoina, A., Tuzun, S., and Scala, F. 1998. Genes from mycoparasitic fungi as a source for improving plant resistance to fungal pathogens. Proc. Natl. Acad. Sci. U.S.A. 95:7860-7865.

Lotan, T., Ori, N., and Fluhr, R. 1989. Pathogenesis-related proteins are developmentally regulated in tobacco flowers. Plant Cell 1:881-887.

Moreno A. B., Martínez del Pozo, Á., Borja, M., and San Segundo, B. 2003. Activity of the antifungal protein from Aspergillus giganteus against Botrytis cinerea. Phytopathology 93:1344-1353.

Murray, M. G., and Thompson, W. F. 1980. Rapid isolation of high molecular weight plant DNA. Nucleic Acid Res. 8:4321-4325.

Nimchuk, Z., Eulgem, T., Holt B. F., and Dangl J. L. 2003. Recognition and response in the plant immune system. Annu. Rev. Genet. 37:579-609.

Ou, S. H. 1985. Rice Diseases, 2nd ed. Commonwealth Mycological Institute, Kew, England.

Pons, M. J., Marfà, V., Melé, E. and Messeguer, J. 2000. Regeneration and genetic transformation of Spanish rice cultivars using mature embryos. Euphytica 114:117-122.

Raventós, D., Jensen, A. B., Rask, M.-B., Casacuberta, J. M., Mundy, J., and San Segundo, B. 1995. A 20-bp cis-acting element is both necessary and sufficient to mediate elicitor response of a maize PRms gene. Plant J. 7:147-155.

Ruiz-Rivero, O., and Prat, S. 1998. A -308 deletion of the tomato LAP promoters is able to direct flower-specific and MeJA-induced expression in transgenic plants. Plant Mol. Biol. 36:639-648.

Rushton, P. J., and Somssich, I. E. 1998. Transcriptional control of plant genes responsive to pathogens. Curr. Opin. Plant Biol. 1:311-315.

Rushton P. J., Reinstädler, A., Lipka, V., Lippok, B., and Somssich, I. E. 2002. Synthetic plant promoters containing defined regulatory elements provide novel insights into pathogen- and wound-induced signaling. Plant Cell 14:749-762.

Sambrook, J., and Russell, D. W. 2001. Molecular Cloning: A Laboratory Manual, 3rd ed. Cold Spring Harbor Laboratory Press, Plainview, NY, U.S.A.

Somssich, I. E., and Hahlbrock, K. 1998. Pathogen-defence in plants: A paradigm of biological complexity. Trends Plant Sci. 3:86-90.

van Loon, L. C. 1985. Pathogenesis-related proteins. Plant. Mol. Biol. 4:111-116.

van Loon, L. C., and van Strien, E. A. 1999. Occurrence and properties of plant pathogenesis-related proteins. Pages 1-20 in: PathogenesisRelated Proteins in Plants. S. K. Datta and S. Muthukrishnan, eds. CRC Press, Boca Raton, FL, U.S.A.

Vila, L., Lacadena, V., Fontanet, P., Martínez del Pozo, A., and San Segundo, B. 2001. A protein from the mold Aspergillus giganteus is a potent inhibitor of fungal plant pathogens. Mol. Plant-Microbe Interact. 14:1327-1331.

Xiang, C., Miao, Z.-H., and Lam, E. 1996. Coordinated activation of as-1type elements and a tobacco glutathione $S$-transferase gene by auxins, salicylic acid, methyl-jasmonate and hydrogen peroxide. Plant Mol. Biol. 32:415-426.

Zasloff, M. 2002. Antimicrobial peptides of multicellular organisms. Nature 415:389-395.

Zhu, Q., Doerner, P. W., and Lamb, C. J. 1993. Stress induction and developmental regulation of a rice chitinase promoter in transgenic tobacco. Plant J. 3:203-212.

\section{AUTHOR-RECOMMENDED INTERNET RESOURCES}

CAMBIA website: www.cambia.org

Plant Care database: intra.psb.ugent.be 